\title{
Perceived Effectiveness, Cost, and Availability of Patient Education Methods and Materials
}

\author{
MARTHA M. FUNNELL, MS, RN, CDE; MICHAEL B. DONNELLY, PhD; \\ ROBERT M. ANDERSON, EdD; PATRICIA D. JOHNSON, MSN, RN; \\ MARY S. OH, BS \\ Michigan Diabetes Research and Training Center \\ University of Michigan \\ Ann Arbor, Michigan
}

To determine the efficacy of and need for patient education methods and media, a needs assessment was sent to 816 members of the American Association of Diabetes Educators. Respondents $(n=325$, $40 \%$ ) included $62 \% R N s, 36 \%$ RDs, $1 \%$ other; $62 \%$ CDEs. Their mean number of years experience in diabetes education was 8.5 , and $99 \%$ routinely provided patient education. Respondents indicated that videotapes and slide tapes were the most educationally effective media and books and audiotapes were the least effective. Booklets and videotapes were the most cost-effective and computer-assisted instruction the least effective. While respondents perceived one-to-one counseling, skills training, and diabetes content sessions to be the three most educationally effective methods, support groups and large and small discussion groups were seen as the three most cost-effective educational methods. Among nine potential barriers to quality patient education listed, educators rated lack of third-party

reimbursement as a major barrier most frequently and national availability of quality education materials as a barrier least frequently.
Diabetes is a chronic illness that requires active patient participation in daily self-care behaviors in order to maintain metabolic control. The regimen is generally complex, and often necessitates life-style changes on the part of the person with diabetes and his or her family. Education about diabetes has become accepted as an integral part of care for the person with diabetes.

For the past 12 years, the Michigan Diabetes Research and Training Center (MDRTC) has been involved with training diabetes educators and developing patient educational materials for use by educators. ${ }^{1-3}$ However, the emphasis in patient teaching has changed in a recent years. There is a growing demand for diabetes education that is both highquality and cost-effective. ${ }^{4.5}$ As a result, the MDRTC believed that an evaluation of the impact of these trends was needed and conducted a comprehensive assessment of the efficacy of, and need for, patient education methods and media. These data can now be used to guide our efforts and the efforts of others in the development of relevant and appropriate continuing education programs and patient education materials.

\section{Methods}

A questionnaire was developed that elicited background information from the diabetes educators, eg, level of education, types of certification, years experience in patient education and, specifically, in diabetes patient education. The survey also contained an assessment of professional activities as well as the type of diabetes education provided and the size and scope of the diabetes patient education programs at the educators' institutions. The second part of the questionnaire (see sidebar) asked the educators to rate seven types of educational materials and eight types of educational methods for both cost and educational effectiveness. They were also asked to rate the extent to which nine barriers interfered with their ability to provide high-quality patient education. The third part of the questionnaire contained an assessment of the educator's use of patient education materi-

\footnotetext{
This study was supported in part by National Institutes of Health Grant NIH2P60DK20572-13 from the National Institute of Arthritis, Digestive, and Kidney Diseases, Bethesda, Maryland.

Reprint requests to Martha M. Funnell, RN, CDE, Michigan Diabetes Research and Training Center, C333 Med-Inn, Box 0832, University Hospitals, Ann Arbor, MI 48109-0832.
} 


\section{Section II: Patient Education}

In this section, we would like you to judge the effectiveness of a number of instructional media/methods for providing education to your patients with diabetes. We realize that different patients have different learning styles and that some topics are best presented in a particular format. However, we would like you to rate these items "in general" - what works best with most of your patients in many situations. Please indicate your rating by circling the number that best represents your judgment. If you never use a medium or method, please circle NU.

Books

Booklets

Programmed instruction/ workbook

Slide/tape

Computer-assisted instruction

Videotapes

Audiotapes

One-to-one counseling session

Support group

Large-group discussion

Lectures

Small-group skills session

Small-group content discussions

One-on-one skills session

One-on-one content instruction

\begin{tabular}{rrrr}
\multicolumn{2}{c}{$\begin{array}{c}\text { Not } \\
\text { Effective }\end{array}$} & \multicolumn{2}{c}{$\begin{array}{c}\text { Sometimes } \\
\text { Effective }\end{array}$} \\
1 & 2 & 3 & 4 \\
1 & 2 & 3 & 4
\end{tabular}

\section{2}

2

2

2

2

2

2

2

2

2

2

2

2

$\begin{array}{ll}3 & 4 \\ 3 & 4 \\ 3 & 4 \\ 3 & 4 \\ 3 & 4 \\ 3 & 4 \\ 3 & 4 \\ 3 & 4 \\ 3 & 4 \\ 3 & 4 \\ 3 & 4 \\ 3 & 4 \\ 3 & 4\end{array}$

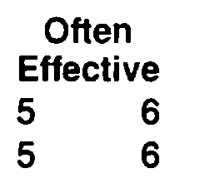

$\begin{array}{cc}\text { Always } & \text { Never } \\ \text { Effective } & \text { Used } \\ 7 & \text { NU } \\ 7 & \text { NU }\end{array}$

$\begin{array}{ll}4 & 5 \\ 4 & 5 \\ 4 & 5 \\ 4 & 5 \\ 4 & 5 \\ 4 & 5 \\ 4 & 5 \\ 4 & 5 \\ 4 & 5 \\ 4 & 5 \\ 4 & 5 \\ 4 & 5 \\ 4 & 5\end{array}$

6
6
6
6
6
6
6
6
6
6
6
6
6

$\mathrm{NU}$

NU

NU

NU

NU

NU

NU

NU

NU

NU

$\mathrm{NU}$

$\mathrm{NU}$

$\mathrm{NU}$

Please estimate the cost-effectiveness of each of the following instructional media/methods. Indicate your rating by circling the number which best represents your judgment. In this case, think of cost-effectiveness as the ratio of cost of the method (including your time) to its educational benefit.

\begin{tabular}{|c|c|c|c|c|c|c|c|c|}
\hline \multirow[b]{2}{*}{ Books } & \multicolumn{2}{|c|}{$\begin{array}{c}\text { Not } \\
\text { Cost-Effective }\end{array}$} & \multicolumn{3}{|c|}{$\begin{array}{c}\text { Moderately } \\
\text { Cost Effective }\end{array}$} & \multicolumn{2}{|c|}{$\begin{array}{c}\text { Very } \\
\text { Cost-Effective }\end{array}$} & \multirow{2}{*}{$\begin{array}{c}\text { Never } \\
\text { Used } \\
\text { NU }\end{array}$} \\
\hline & 1 & 2 & 3 & 4 & 5 & 6 & 7 & \\
\hline Booklets & 1 & 2 & 3 & 4 & 5 & 6 & 7 & NU \\
\hline $\begin{array}{l}\text { Programmed instruction/ } \\
\text { workbook }\end{array}$ & 1 & 2 & 3 & 4 & 5 & 6 & 7 & $\mathrm{NU}$ \\
\hline Slide/tape & 1 & 2 & 3 & 4 & 5 & 6 & 7 & NU \\
\hline Computer-assisted instruction & 1 & 2 & 3 & 4 & 5 & 6 & 7 & NU \\
\hline Videotapes & 1 & 2 & 3 & 4 & 5 & 6 & 7 & NU \\
\hline Audiotapes & 1 & 2 & 3 & 4 & 5 & 6 & 7 & NU \\
\hline One-to-one counseling session & 1 & 2 & 3 & 4 & 5 & 6 & 7 & NU \\
\hline Support group & 1 & 2 & 3 & 4 & 5 & 6 & 7 & NU \\
\hline Large-group discussion & 1 & 2 & 3 & 4 & 5 & 6 & 7 & NU \\
\hline Lectures & 1 & 2 & 3 & 4 & 5 & 6 & 7 & NU \\
\hline Small-group skills session & 1 & 2 & 3 & 4 & 5 & 6 & 7 & NU \\
\hline Small-group content discussions & 1 & 2 & 3 & 4 & 5 & 6 & 7 & NU \\
\hline One-on-one skills session & 1 & 2 & 3 & 4 & 5 & 6 & 7 & NU \\
\hline One-on-one content instruction & 1 & 2 & 3 & 4 & 5 & 6 & 7 & NU \\
\hline
\end{tabular}


als and content areas for which additional materials needed to be developed.

The survey was mailed to 816 randomly selected members of the American Association of Diabetes Educators; 500 were registered nurses (RNs) and 316 were registered dietitians (RDs). Three hundred twenty-five surveys were returned for a response rate of $40 \%$. Frequency distributions were calculated for all the questions. Comparisons among items in the areas of educational materials or methods, barriers to education, and content areas of need were conducted by using repeated measures analysis of variance with Scheffé post hoc tests. Areas prioritized by the respondents were grouped using Scheffé post hoc test determinations of significant differences among items.

\section{Results}

Background and Practice Information Sixty-two percent of the respondents were RNs, $36 \%$ were RDs, and $1 \%$ were other. The average age was 41 years (range 23 to 70 ). Nine percent of the sample had nursing diplomas, $3 \%$ had associate degrees, $49 \%$ had bachelor's degrees, $36 \%$ had master's degrees, and $62 \%$ of the educators were certified diabetes educators (CDEs). The educators in this study had an average of 11.5 years (range 1 to 40 ) experience in patient education, and a mean of 8.5 years (range 1 to 36 ) of diabetes education. They spent just under 14 hours a week on average providing diabetes patient education in a variety of settings. The average number of hours worked was 37 ; the range ( 2 to 80 ) and standard deviation (10.94) suggest a considerable variability, in the number of hours worked per week (see Table 1). More one-to-one than group sessions were provided, and almost equal numbers of inpatients and outpatients were educated. Inpatient programs were offered on a weekly basis while outpatient education programs were offered about twice a month. The outpatient programs had more scheduled hours, were more expensive, and offered more follow-up contacts per patient. However, there was a wide range in the responses to these questions (see Table 2).

Educational Materials and Methods The educators were asked to rate six different types of educational materials and eight different educational methods for both educational effectiveness and cost-effectiveness. There was general agreement between the ratings for effectiveness of materials, with videotapes, booklets, and slide/tape programs seen as both educationally effective and cost-effective. There was less agreement between the effectiveness ratings for educational methods. Individual skill and content teaching sessions were highly rated for educational effectiveness but received the lowest ratings for cost-effectiveness. Individual counseling sessions were seen as generally both educationally effective and cost-effective; however, there was a decline in the overall mean for cost-effectiveness (see Tables 3 and 4).

The educators were asked to indicate whether each of nine barriers listed on the questionnaire was a major barrier, a minor barrier, or not a barrier to high-quality patient education. The barriers most frequently identified as major were the lack of third-party reimbursement for diabetes education and unmotivated patients. Lack of high-quality materials was perceived as a minor barrier, while the cost of the materials was seen as a moderate barrier (see Table 5).
Table 1. Hours Spent on Diabetes Education Activities per Week

$\begin{array}{lcc}\text { Educational Setting } & \text { Mean } & \text { Range } \\ \text { Hospital inpatient }(n=200) & 15.8 & (1-59) \\ \text { Hospital outpatient }(n=208) & 12.6 & (1-70) \\ \text { Public health/home care }(n=25) & 10.0 & (1-40) \\ \text { Clinic/physician's office }(n=73) & 15.3 & (1-40) \\ \text { Other }(n=63) & 12.0 & (1-40)\end{array}$

Table 2. Profile of Diabetes Education Programs

Number of Patients Educated Per Year

$\begin{array}{llc} & \text { Mean } & \text { Range } \\ \text { Outpatient individual }(n=253) & 227 & (1-4,000) \\ \text { Outpatient group }(n=178) & 192 & (3-12,410) \\ \text { Inpatient individual }(n=191) & 212 & (1-7,300) \\ \text { Inpatient group }(n=81) & 189 & (1-1,200)\end{array}$

Education Program Characteristics

\begin{tabular}{|c|c|c|}
\hline & Mean & Range \\
\hline \multicolumn{3}{|l|}{ Inpatient } \\
\hline Average charge $(n=40)$ & $\$ 91.13$ & $(\$ 0-500)$ \\
\hline No. times offered per year $(n=60)$ & 58.7 & $(1-365)$ \\
\hline $\begin{array}{l}\text { No. hours to complete program } \\
(n=95)\end{array}$ & 9.0 & $(1-79)$ \\
\hline $\begin{array}{l}\text { No. follow-up contacts per patient } \\
(n=76)\end{array}$ & 3.7 & $(1-100)$ \\
\hline \multicolumn{3}{|l|}{ Outpatient } \\
\hline Average charge $(n=130)$ & $\$ 125.99$ & $(\$ 0-850)$ \\
\hline No. times offered per year $(n=164)$ & 22.7 & $(1-400)$ \\
\hline $\begin{array}{l}\text { No. hours to complete program } \\
\qquad(\mathrm{n}=181)\end{array}$ & 11.7 & $(1-100)$ \\
\hline $\begin{array}{l}\text { No. follow-up contacts per patient } \\
(n=168)\end{array}$ & 4.5 & $(1-90)$ \\
\hline
\end{tabular}

Types of Educational Services Provided by Respondents

$\begin{array}{lcc} & \text { No. } & \% \\ \text { Individual teaching (not nutrition) } & 235 & 72 \\ \text { Individual nursing assessment } & 182 & 56 \\ \text { Individual nutrition counseling } & 154 & 47 \\ \text { Individual nutrition assessment } & 143 & 44 \\ \text { Group teaching (not nutrition) } & 137 & 42 \\ \text { Individual behavioral/psychos } \propto \text { cial } & & \\ \quad \text { counseling } & 131 & 40 \\ \text { Support group } & 118 & 36 \\ \text { Group nutrition teaching } & 89 & 27 \\ \text { Other } & 34 & 10\end{array}$


Table 3. Ratings of Educational Effectiveness*

$\begin{array}{lr}\text { Educational materials } & \text { Mean } \\ \text { Generally effective }{ }^{\dagger} & \\ \text { Videotapes } & 5 \\ \text { Slide/tapes } & 4 \\ \text { Booklets } & 4 \\ \text { Moderately effective }{ }^{\dagger} & \\ \text { Programmed instruction } & 4 \\ \text { Rarely effective }{ }^{\dagger} & \\ \text { Audiotapes } & 3 \\ \text { Computer-assisted instruction } & 3.6 \\ \text { Books } & 3.6\end{array}$

F between items $=68.6 ; P<.001$.

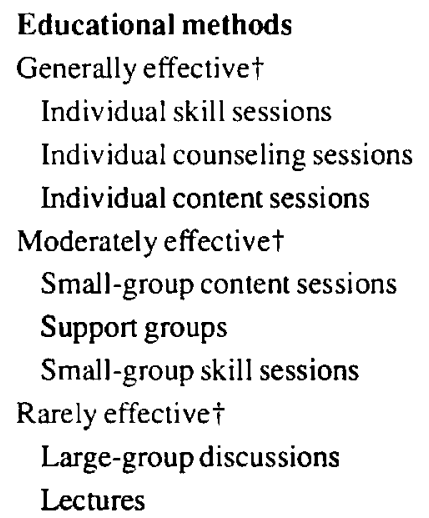

Mean

Repeated measures ANOVA: $F$ between items $=77.4 ; P<.001$.

* Not effective $=1$ : al ways effective $=7$.

$\dagger$ Groupings by level of effectiveness were determined using Scheffé post hoc tests $(P<.01)$. A category break was taken to occur where a significant difference with the highest rated item in the preceding category first appeared.

Patient education resources such as media and print materials are important components of many diabetes education programs. ${ }^{+6}$ Because of their importance in the educational process, we asked several additional questions concerning the use of materials. Virtually all (99\%) of the respondents used booklets and $90 \%$ used videotapes in their educational programs while very few used computer-assisted programs (14\%). The factor rated as crucial for materials selected most often was applicability, with cost of materials selected least often (see Table 6). The respondents indicated that they obtained their educational materials from drug/manufacturing companies $(88 \%)$, developed their own (84\%), or purchased them from other sources $(60 \%)$. The major source of funding for purchasing materials was through the provider of the programs, either as a service or as part of the program fee. The major sources of information about new materials were identified as professional meetings (87\%) and company representatives $(83 \%$ ) (see Table 7 ).

To identify the content areas for which additional highquality educational materials are needed, the educators were asked to rate 31 different topics on a scale of 1 through 7 ,
Table 4. Ratings of Cost-effectiveness*

$\begin{array}{lc}\text { Educational materials } & \text { Mean } \\ \text { Generally cost-effective } † & \\ \text { Booklets } & 5.4 \\ \text { Videotapes } & 5.3 \\ \text { Moderately cost-effective } † & \\ \text { Slide/tapes } & 4.7 \\ \text { Audiotapes } & 4.3 \\ \text { Programmed instruction } & 4.0 \\ \text { Rarely cost-effective } \dagger & \\ \text { Books } & 3.6 \\ \text { Computer-assisted instruction } & 3.1\end{array}$

F between items $=62.4 ; P<.001$.

Educational methods

Mean

Generally cost-effectivet

Support groups

5.3

Large-group discussions $\quad 5: 2$

Small-group skill sessions $\quad \mathbf{5 . 1}$

Small-group content sessions $\quad 5.1$

Lectures $\quad 4.9$

Individual counseling sessions $\quad 4.9$

Moderately cost-effective $\dagger$

Individual skill sessions

4.6

Individual content sessions

4.6

Repeated measures ANOVA: F between items $=9.3 ; P<.001$

*Not effective $=1:$ al ways effective $=7$.

$\uparrow$ Groupings by level of effectiveness were determined using Scheffé post hoc tests $(P<.01)$. A category break was taken to occur when a significant difference with the highest rated item in the preceding category first appeared.

with 7 equal to great need and 1 equal to no need. For analytic purposes, these 31 topics were grouped into seven broader content areas (see Table 8 ). Psychological and social aspects were identified as the area of greatest need, with special populations. complications, and nutrition as areas with some need for materials development.

\section{Discussion}

The respondents to this survey represent well-educated, experienced diabetes educators of whom $85 \%$ have a bachelor's degree or higher and $62 \%$ have obtained certification as diabetes educators. This is not surprising given that they were selected from the American Association of Diabetes Educators (currently $67 \%$ of the membership has a bachelor's degree or higher; $51 \%$ are CDEs) and these qualifications are consistent with diabetes educator positions. They provide education in a variety of health care settings, and the average number of hours worked represents a fulltime work commitment. Most educators who provided education in a hospital setting reported spending time educating both inpatients and outpatients, perhaps a reflection of the many hospitals in which one person is responsible for all 
Table 5. Barriers to High-Quality Patient Education*

\section{Educational Barriers}

Mean

Major bartiers $\dagger$

Lack of third-party reimbursement

Unmotivated patients

Moderate barriers $\dagger$

Cost of diabetes education materials

Lack of financial resources/support

Lack of physician support/referral

Lack of high-quality materials locally

Minor barriers $\dagger$

Lack of continuing education opportunities

Patient education not valued by employer

Lack of high-quality materials nationally
1.9

Table 7. Resources for Materials Used

\section{Sources for Materials}

$\begin{array}{lll} & \text { No. } & \% \\ \text { Drug/manufacturing companies } & 285 & 88 \\ \text { Developed own } & 273 & 84 \\ \text { Purchased from other sources } & 196 & 60\end{array}$

Repeated measures ANOVA: $\mathrm{F}$ between items $=83.1 ; P<.001$.

* Major barrier $=1$ : not a barrier $=3$.

† Groupings by level of effectiveness were determined using Scheffé post hoc tests $(P<.01)$. A category break was taken to occur where a significant difference with the highest rated item in the preceding category first appeared.

Table 6. Profile of Educational Materials Used

\section{Types of Materials}

Booklets

Videotapes

Books

Slides/tapes

Audiotapes

Programmed instruction

Computer-assisted instruction

No. $\%$

317

281

265

219

141

111

33

\section{Factors in Choosing Materials*}

$\begin{array}{lccc} & \text { Mean } & \%=1 & \%=5 \\ \text { Applicability } & 4.5 & 0.3 & 61 \\ \text { Ease of use } & 4.3 & 0.3 & 51 \\ \text { Reading level } & 4.2 & 0.6 & 49 \\ \text { Ease of obtaining } & 3.7 & 2.0 & 27 \\ \text { Cost } & 3.7 & 4.0 & 28\end{array}$

* 1 = not a factor; 5 = crucial factor.

\section{Major Source of Funding for Materials}

$\begin{array}{lcc} & \text { No. } & \% \\ \text { Hospital provides as a service } & \mathbf{9 9} & 32 \\ \text { Included in program cost } & 77 & 25 \\ \text { Use only free materials } & \mathbf{7 9} & 26 \\ \text { Develop own } & 35 & 11 \\ \text { Charge patients directly } & 18 & 6\end{array}$

\section{Source of Information about New Materials}

$\begin{array}{lll} & \text { No. } & \text { \% } \\ \text { Professional meetings } & 284 & 87 \\ \text { Drug company representatives } & 270 & 83 \\ \text { Journal articles } & 251 & 77 \\ \text { Joumal advertisements } & 241 & 74 \\ \text { Word of mouth } & 221 & 68 \\ \text { Reviews in journals } & 219 & 67\end{array}$

Table 8. Content Areas Needing More Educational Materials

Content Areas

Mean

Great need $\dagger$

Psychological and social aspects

(eg, adjustment, stress, family support)

Some need $\dagger$

Special populations

(eg. children, teens, elderly, minorities)

Long-term complications

(eg, sexual health, retinopathy)

Nutrition

(eg, weight loss)

Limited need $\dagger$

Short-term complications

(eg, hypoglycemia, ketoacidosis)

Non-dietary treatment

(eg, insulin, pills, exercise)

Pathophysiology diabetes education throughout the institution. The educators reported providing a wide range of services generally considered appropriate for diabetes educators. Therefore, while the response rate for the survey was low, we believe that this group of highly trained, experienced diabetes educators represents both the membership and leadership of this profession, and their perceptions should be taken into account by those who create patient education materials.

Patients educated on a one-to-one basis in an outpatient setting made up the single largest group of patients. An
Repeated measures ANOVA: F between items $=86.7 ; P<.001$.

$*$ No need $=1$; greatest need $=7$.

$\dagger$ Groupings by level of effectiveness were determined using Scheffé post hoc tests $(P<01)$. A category break was taken to occur where a significant difference with the highest rated item in the preceding category first appeared. 
almost equal number of patients were educated on an inpatient basis by a much smaller number of educators. These numbers may be related to the frequency with which inpatient programs are offered, which is almost three times as often as outpatient programs. A larger number of educators responded to questions about outpatient education program characteristics than responded to questions about inpatient program characteristics. The outpatient programs were more expensive to patients and were offered less frequently but had more scheduled hours and offered an average of one more follow-up visit per patient.

Individual education and counseling are the teaching methods most frequently used by these educators and were identified as most educationally effective by them. However. individual teaching was rated as the least cost-effective method by these educators. This indicates a dilemma in that the teaching methods perceived as most educationally sound and most frequently used by diabetes educators are not believed to be cost-effective.

This sample of diabetes educators identified the lack of third-party reimbursement as a major barrier to quality patient education. While the Centers for Disease Control (CDC) report an increase in both the number of states (up to 31) that now have some form of reimbursement for outpatient diabetes education and the number of programs, reimbursement is generally available only for complete programs and for those that are recognized or approved. In addition. the advent of diagnostic-related groups (DRGs) has effectively eliminated reimbursement for inpatient education.? The fewer number of inpatient programs reported that charged a fee ( $n=40$ versus $n=130$ ) and lower rates appear to reflect that trend. Many hospitals are currently experiencing financial problems leading to cutbacks in programs that are not viewed as revenue-generating or cost-effective. Thus, it would appear that these financial concerns could ultimately have a negative impact on both the perceived quality and quantity of diabetes education services provided by these educators, particularly in the inpatient setting.

Diabetes educators use a variety of educational materials in providing information to patients. Booklets and videotapes were the most frequently used materials and were identified as both cost-effective and educationally effective by these educators. Booklets are widely available, often at no direct cost to the education program. They are frequently used as a resource in the teaching process, to reinforce content, and as take-home material for the patient to review. ${ }^{8}$ Thus, the almost universal use of booklets by educators is not surprising. Educators indicated that they believe computer-assisted instruction to be rarely educationally effective or cost-effective and used by only a small number of this sample. This may be due to lack of access to computers by patients and educators, the quality of computer programs currently available, the perceived lack of computer literacy among adults, or the associated costs. Surprisingly, although books were rated as rarely educationally effective or cost-effective, they were used by $81 \%$ of the respondents.

The fact that the lack of patient motivation is seen as a major barrier to high-quality diabetes education is of concern. This may indicate the educator's frustration with having to spend a great deal of time and energy cajoling patients to take part in the educational program, convincing patients to adhere to the treatment plan, and then re-educating patients who experience acute complications of diabetes, perhaps as a result of lack of adherence. This perception may also be linked with the financial concerns indicated earlier. Patients who are unwilling or unable to pay for outpatient diabetes education programs out of pocket may be viewed as unmotivated. If the success, and therefore the continued funding, of a diabetes education program is based on the program's ability to generate income, limited attendance can have a negative impact on its viability. Additionally, if the facility physicians evaluate the educational program based on patient compliance, a program viewed as unsuccessful in motivating patients may receive fewer referrals and may be more likely to face funding cuts or elimination.

Applicability and ease of use were identified as the two most important factors when choosing educational materials. Cost of the materials was identified as the least important consideration. This is different from earlier findings where cost was the dominant factor in materials selection. ${ }^{6}$ However, the earlier survey was done in only one state and may reflect the status of reimbursement for education in that particular state, while these data are from a national sample. In addition, the large number of educators using free or self-developed materials, and the willingness of institutions to provide materials as a service or to include the cost of materials in the program fee among this group of educators may also be pertinent factors.

The lack of availability of educational materials was not viewed as a barrier to providing quality education by the respondents. That educators perceive only a limited need to develop materials for the most traditional content areas is not surprising given the number of available booklets, pamphlets, and videotapes related to these areas. ${ }^{6}$ However, the educators did identify a need for the development of materials related to psychosocial issues, special populations of patients, and long-term cờmplications. The need for materials related to the psychological and social aspects of diabetes may reflect the educators' perception that they are less skilled in these areas and believe that their educational effectiveness could be improved through the use of media. Because psychological aspects can have an impact on patient motivation and adherence, the desire for materials in this area may be related to the issue of unmotivated patients identified earlier. The educators may perceive that if both they and their patients were more knowledgeable about psychosocial issues, they could then successfully apply this knowledge to increase motivation and the quality of the education program.

Psychosocial aspects, the long-term complications of diabetes, and nutritional issues related to behavior change represent some of the most difficult aspects of diabetes education from the perspectives of patients and educators. For example, it is difficult both to hear about and to talk about the potential for the long-term complications of diabetes. The need to lose weight is a continuing and often frustrating problem for patients and educators. Given that educators believe that the use of media enhances educational effectiveness, the need for additional materials in these problematic areas is not surprising. In addition, specific groups of patients, such as children, minorities, and the elderly, have been somewhat neglected in the more general patient educa- 
tion materials that are currently available. The identification of this need is an indication of the increasing recognition by these educators of the importance of targeting information for groups of patients.

In summary, the respondents to this questionnaire appear to represent a group of well-educated and experienced diabetes educators. They indicated lack of reimbursement as the major barrier to high-quality patient education, particularly as it relates to the educational method used. They further identified a need for materials development related to psychological and social aspects of diabetes care. Diabetes centers and others who are responsible for patient and professional education need to use these results to develop relevant and appropriate materials.

\section{References}

1. Knopf RF, Kittel PRE. Funnell MM, Wolf FM. Development and evaluation of diabetes continuing education courses for health professionals: a synthesis of eight years experience. Diabetes Educ 1988; 14:136-41.
2. Wolf FM, Sherwood LS, Barr PA, Funnell MM. Evaluation of "Life with Diabetes" patient education booklets. Diabetes Educ 1986;12:51-54.

3. Funnell MM, Barr PA, Frey ML, Palchik NS. Templeton CL. Development of a curriculum for type II diabetes education. Top Clin Nutr 1988:34:40-45

4. DeMuth JS. Patient teaching in the ambulatory setting. Nurs Clin North Am 1989:24:645-54.

5. Ruzicki DA. Realistically meeting the needs of hospitalized acute and short-stay patients. Nurs Clin North Am 1989;24:629-37.

6. Bowbeer MM, Hiss RG. Use of educational resources in diabetes patient education [Letter]. Diabetes Educ 1990;16:15.

7. Peddicord M, Lyons A. Tobin C, Vinicor F. Third-party reimbursement for diabetes mellitus. Diabetes Spectrum 1990:3(1):9-12.

8. Farrell-Miller P. Gentry P. How effective are your patient education materials? Guidelines for developing and evaluating written educational materials. Diabetes Educ 1989;15:418-22. 